\title{
Gida Ambalajı Olarak Kullanilan PVC Plastik Malzemelerde Ftalatların Gaz Sıvı Kromatografisi-ECD Yöntemi ile Tayini
}

Determination of Phthalates in PVC Plastic Materials Used in Food Packaging by Electron Capture Gas Chromatography

\section{Ö Z E T}

G1da ambalajı olarak kullanılan PVC plastiklerine plastifiyan olarak katılan ftalatların, bu malzemelerde tayini için bir yöntem geliştirilmiştir. PVC plastiklerindeki ftalat esterlerinin miktar tayinlerinde, gaz kromatografisi elektron yakalama dedektörü ile duyarlı sonuçlar elde edilmiştir.

Türkiye'de üretilen bazı PVC g1da ambalaj malzemelerinin ftalat içerikleri geliştirilen bu yöntem uygulanarak araştırılmıştır. Sonuçlar (\% $0.8-\%$ 6.4) konulan sınırların altında saptanmıştır.

\section{SUMMARY}

A method is described for the identification of phthalate plasticizers commonly used in PVC plastic materials used in food packaging. A very sensitive result for the determination of phthalate esters in PVC compounds was obtained by using a gas chromatography with electron capture detector.

The content of phthalates in some PVC containers manufactured in Turkey were investigated by the application of the method developed. The results (\% $0.8-\% 6.4$ ) were found under the tolerance limits.

\section{Anahtar Kelimeler}

PVC g1da ambalaj malzemeleri, DEHP, D İO P, DBP, DİB P, DEP, DİDP, Gaz sıvı kromatografisi-ECD

Redaksiyona verildiği tarih: 15.1.1987

* Farmasötik Toksikoloji Anabilim Dalı, Eczacılık Fakültesi, Ankara Üniversitesi. 
Son yıllarda plastik kullanımının ve buna paralel olarak plastiklerin gida ambalajlanmasında kullanımının hızla artması, bu maddelerin toksikoloji yönünden ayrıntılı olarak değerlendirilmelerini gerektirmektedir.

Genellikle plastiklerin toksik etkilerinden monomerleri ve üretimlerinde geniş oranda kullanılan katkı maddeleri sorumludur (1-6).

Plastik bir madde, yapısında, esasını polimer bir madde teşkil etmek üzere değişen miktarlarda da çeşitli katkı maddelerini içerir. Bu küçük moleküllü maddeler plastik içinde polimerlerin aksine hareket halindedirler. Bu nedenle bu maddelerin gidaya geçebilmeleri mümkün olmaktadir (7-11). Önlem olarak geçebilen maddeler için yönetmeliklerde bazı sınırlamalar getirilmiş ise de devamlı kontroller yoluyla bu maddelerin katılış oranları, gıdaya geçişleri ve getirebilecekleri sonuçlar gözlenmelidir.

Plastiklerden polivinilklorürün (PVC) ve VG kopolimerlerinin gıda ambalajlanmasında kullanımı son yıllarda hızla artmıştır. Ftalatlar, bu plastiklere plastifiyan (yumuşatıcı) olarak katılan önemli bir grubu oluşturmaktadır. Bu grubun toplam plastifiyan kullanımının yaklaşık \% 90'ını oluşturduğu bildirilmektedir (12). Kullanılan en önemli ftalat di (2-etilhekzil) ftalat (DEHP) (Dioktil ftalat) tır. Amerika Birleşik Devletleri'nde 1979'da kullanılan 138 milyon kg DEHP'ın bu ülkede tüketilen ftalatların yaklaşık \% 26'sını oluşturduğu bildirilmektedir. (12).

Amerika Birleşik Devletleri'nde National Toxicology Program'in çalışmaları sonucu DEHP'ın fare ve sıçanlarda karaciğer tümörüne neden olduğunun bulunması ve bununla ilgili yayını takiben bu madde üzerindeki araştırmalar yoğunlaşmıştır. DEHP'ın karsinojenik etkileri hakkındaki son değerlendirmede Dünya Sağlık Örgütü'ne bağlı Kanser Araştırma merkezi (IARC) bu maddenin fare ve sıçanlarda karsinojenik etkileri ile ilgili yeterli delil olduğunu bildirmektedir(12).

Çeşitli araştırmalar DEHP'ın sıçanlarda testiküler harabiyete neden olabileceğini göstermiştir(13). Yine bazı araştırıcılar tarafından DEHP ve major metaboliti mono(2-etilhekzil) ftalat (MEHP)'ın fare ve sıçanlarda teratojenik ve embriyoletal etkileri olduğu bildirilmektedir (14-16).

Bir karaciğer karsinojeni olarak bildirilen ve PVC plastiklerine \% 40'a varan yüksek oranlarda katılabilen DEHP, ülkemizde de üretilmekte ve yaygın olarak kullanılmaktadır. Çalışmamızda, ülkemiz- 
de üretilen ve plastifiyan olarak PVC plastiklerine katılan ftalatların, plastik malzemeden tayini için bir yöntem kurulması amaçlanmıştır. $\mathrm{Bu}$ amaçla önce ince tabaka kromatografisi (İTK) ile ön tanıma ve sonra gaz sıvı kromatografisi-ECD ile nicel tayin için yöntem kurul muştur. Bu yöntem kullanılarak gida ambalajı olarak kullanılan sert ve yumuşatılmış PVC örneklerinde ftalatların varlı̆̆ı ve katılma oranları saptanmıştır.

\section{DENEL KISIM}

\section{Materyal}

Ftalat Standartları: Di (2-ctilhekzil) ftalat (DEHP) (EPA), di-izooktil ftalat (DİOP) (Marshall), dibutil ftalat (DBP) (Petkim), di-izobutil ftalat (DİBP) (Marshall), dietil ftalat (DEP) (EPA), di-izodesil ftalat (DİDP) (Plastel).

\section{Örnekler}

1- Türkiye'de üretilen çeşitli firmalara ait, gıda ambalajında kullanılan yumuşatılmış PVC film malzemeler,

2- Türkiye'de üretilen, şişirme-kalıplama yöntemiyle şekil verilmiş özellikle sıvı bitkisel yağ ve sirkenin konulduğu sert PVC şişe örnekleri seçilmiştir.

Kullanilan Aletler: Gaz kromatograf (Packard-Becker Model 419), İTK takımı (Desega).

\section{Metod}

\section{Ftalatların PVC Örneklerinden Ekstraksiyonu (17)}

PVC film ve şişe örnekleri 5'er mm'lik kareler halinde kesildi, l'er g tartılarak sokselet cihazının kağıt kartuşlarına yerleştirildi. Karbon tetraklorür-metanol (2:1) karışımı ile 16 saat ekstrakte edildi. Ekstrakt soğutularak süzüldü ve çözücüsü tamamen uçurularak kalıntı, gravimetrik yöntemle hesaplandı ve metanolde çözülerek İTK ve gaz siv1 kromatograf isine uyguland.

\section{Ftalatların İTK'da Nitel Tayinleri}

Referans standart olarak seçilen ftalatların metanoldeki \% 1 Tik çözeltileri hazırlandı. Developman çözücüsü olarak dietil eter /60-70 petrol eteri (20:80) çözücü sistemi, denenen diğer sistemler içerisinden seçilerek kullanılmıştır. Ftalatlar $0.25 \mathrm{~mm}$ kalınlığında silikajel-G plaklara, $2.5 \mu$ ve $5 \mu$ uygulanarak daha önceden çözücü ile doyu- 
rulmuş tanklara yerleştirildi. Çözücü $10 \mathrm{~cm}$ yükselince plak tanktan çıkarılıp oda sıcaklığında kurutuldu. Sonra aşağıdaki belirteçler (18) birbiri ardisıra uygulandı. Önce \% 20 resorsinol (etanolde) ve sonra $4 \mathrm{~N}$ sülfürik asit püskürtüldü. Plak 20 dakika $135^{\circ} \mathrm{C}^{\prime} \mathrm{de}$ bekletildi. \% 25'lik sodyum hidroksit püskürtülerek lekeler belirlendi.

\section{Ftalatların Gaz Sivi Kromatografisi-ECD ile Nicel Tayin- leri}

ECD $\left(\mathrm{Ni}^{63}\right)$ ve \% 3 SE-30 sabit faz olarak kullanıldı. İzotermal koşulda $215^{\circ} \mathrm{C}^{\prime} \mathrm{de}$ çalışıldı. İnternal standart olarak di n-oktil ftalat kullanıldı.

\section{PVC Örneklerinde Polimer Tayini}

Beilstein testi ve soğuk piridin yöntemleri uygulanarak yapılmıştir (19).

SONUÇ ve TARTIŞMA

Çalışmamız kapsamında, referans standart seçilen ftalatların dietil eter/60-70 petrol eteri (20:80) çözücü sistemindeki Rf değerleri ve \% 20 resorsinol, $4 \mathrm{~N}$ sülfürik asit, \% 25 sodyum hidroksit belirteçlerinin sırayla püskürtülmesiyle elde edilen renkler Tablo l'de gösterilmiştir. Ayrıca tabloda görüldüğ̈ gibi ftalatların bu koşullarda verdiği Rf değerleri ve renkler adipatlarla karşılaştırılmıştır.

Tablo 1 incelendiği zaman İTK'da ftalatların renk belirteçleri ile turuncu-kahve lekeler verdiği görülmektedir. Bu lekeler kazınıp $5 \mathrm{ml}$ su ile karıştırıldı̆̆ında yeşil fluoresans verdikleri gözlenmiştir. Ülkemizde plastifiyan olarak ftalatlardan sonra en çok kullanılan grup adipatlardır. Adipatlar ayni renk belirteçleri ile mor renk oluşturmaktadırlar(18). Bu sonuç plastifiyan olarak adipat kullanılan plastik örneklerini kolayca ayırmamıza yardımcı olmuştur.

Tablo 1. Ftalatların dietil eter/60-70 petrol eteri (20:80) çözücü sistemindeki Rf değerlerinin ve renk belirteçleri ile oluşturdukları renklerin adipatlarla karşılaştırılması

\begin{tabular}{|l|c|c|}
\hline Standartlar & Rf & Oluşan Renk \\
\hline Dibutil ftalat & 0.47 & Turuncu-kahve \\
Dietil ftalat & 0.30 & Turuncu-kahve \\
Di-izobutil ftalat & 0.50 & Turuncu-kahve \\
Di-izodesil ftalat & 0.64 & Turuncu-kahve \\
Di-2-etilhekzil ftalat & 0.62 & Turuncu-kahve \\
Di-izooktil ftalat & 0.59 & Turuncu-kahve \\
Dioktil adipat & 0.62 & Mor \\
Di-izooktil adipat & 0.60 & Mor \\
\hline
\end{tabular}


Ftalat referans standartlarının gaz sivı kromatografisi-ECD'de belirtilen koşullarda elde edilen kromatogramları Şekil l'de gösterilmiştir.

Plastik örneklerinde ve çevrede ftalatların aranması ve miktar tayininde gaz sıv1 kromatografisi-ECD (20, 21), gaz sıv1 kromatografisi-FID (22), yüksek basınçlı sıvı kromatografisi-UV dedektör (9, 23) gibi yöntemler kullanılmıştır. Çalışmamızda bu amaçla gaz sıvı kromatografisi -EGD kullanılmıştır. Ftalatlar rezonans mekanizması ile elektron yakalama özelliğine sahiptirler(20). Bu nedenle EC dedektör, ftalatlar için daha hassas ve spesifik olmaktadır. Kullandı̆̆ımız bu yöntemle ftalatların duyarlık sınırları $25 \mathrm{ng}-50 \mathrm{ng}$ arasında saptanmıştır.

Ülkemizde üretilen ve gida ambalajı olarak kullanılan PVC film ve şişe örneklerine yukarıda anlatılan sokselet ekstraksiyon yöntemi uygulanmış, elde edilen toplam ekstrakt (kalıntı) değerleri Tablo 2'de gösterilmiştir. Bu kalıntı içinde ftalatların yanında karbon tetraklorür ve metanolde çözünebilen aril alkil fosfitler-gibi stabilizanlar ve lubrikantlar bulunabilmektedir. Kalıntıda ftalatların varlığı İTK ile tesbit edildikten sonra, gaz sivı kromatografisi ile miktar tayinleri yapılmıştır. Şekil 2'de bir PVC film örneğinden elde edilen ekstraktın gaz sıvı kromatografisi-ECD'deki kromatogramı görülmektedir.

Tablo 2. Çeşitli firmalara ait PVC film ve şişe örneklerinin karbon tetraklorür-metanol (2:1) karışımı ile ekstraksiyonu sonunda elde edilen toplam ekstrakt ve ftalat miktarları

\begin{tabular}{|c|c|c|c|c|c|c|c|c|}
\hline \multirow{2}{*}{ örnek (n:3) } & \multicolumn{4}{|c|}{$\begin{array}{l}\text { Toplam Ekstrakt } \\
\text { (kalınt1) }\end{array}$} & \multicolumn{3}{|c|}{ Toplam Ftalat } & \multirow[t]{2}{*}{$\begin{array}{l}\text { Kalıntıdaki } \\
\text { Ftalat \% si }\end{array}$} \\
\hline & $\mathrm{mg} /$ & $\mathrm{g}$ & & $\%$ & $\mathrm{mg} / \mathrm{g}$ & SD & $\%$ & \\
\hline $\begin{array}{c}1 \quad \text { ( PVC sıvı yağ) } \\
\text { şişesi }\end{array}$ & 41 & \pm & 3.0 & 4.1 & 10.8 & \pm 0.9 & 1.1 & 26 \\
\hline 2 (PVC sirke şişesi) & 27 & \pm & 1.0 & 2.7 & 7.5 & \pm 0.6 & 0.8 & 27.7 \\
\hline 3 (PVC film) & 73 & \pm & 7.5 & 7.3 & 38.1 & \pm 6.2 & 3.8 & 52.2 \\
\hline 4 (PVC film) & 63.6 & \pm & 9.4 & 6.4 & 47.8 & \pm 2.0 & 4.8 & 75.1 \\
\hline 5 (PVC film) & 92 & \pm & 11.0 & 9.2 & 64.4 & $\pm \quad 5.6$ & 6.4 & 70.0 \\
\hline
\end{tabular}

Tablo 2 incelendiğinde, PVC şişe örneklerindeki ftalat \% 'sinin, PVC film örneklerinden daha düşük olduğu görülmektedir. Bununda nedeni, PVC film malzemelerine daha fazla esneklik kazandirmak amaciyla ftalatların katılma oranının artmasıdır.

Sağlık ve Sosyal Yardım Bakanlığı "Gıda Maddeleri ile Temasta Bulunan veya Bulunmak Üzere İmal Edilen Plastikler Hakkında Yö- 
Sabit faz: \% 3 SE-30

Dedektör: ECD

Azot akış hızı: $40 \mathrm{ml} / \mathrm{dak}$

Hidrojen akış hızı: $30 \mathrm{ml} / \mathrm{dak}$

Hava akış hızı: $300 \mathrm{ml} / \mathrm{dak}$

Firın sicaklığı: $215^{\circ} \mathrm{C}$

Enjeksiyon sicaklı̆̆ $1: 260^{\circ} \mathrm{C}$

Dedektör sicaklığ $1: 280^{\circ} \mathrm{C}$

Att: 16

Kaydedici hızı: $0.5 \mathrm{~cm} / \mathrm{dak}$

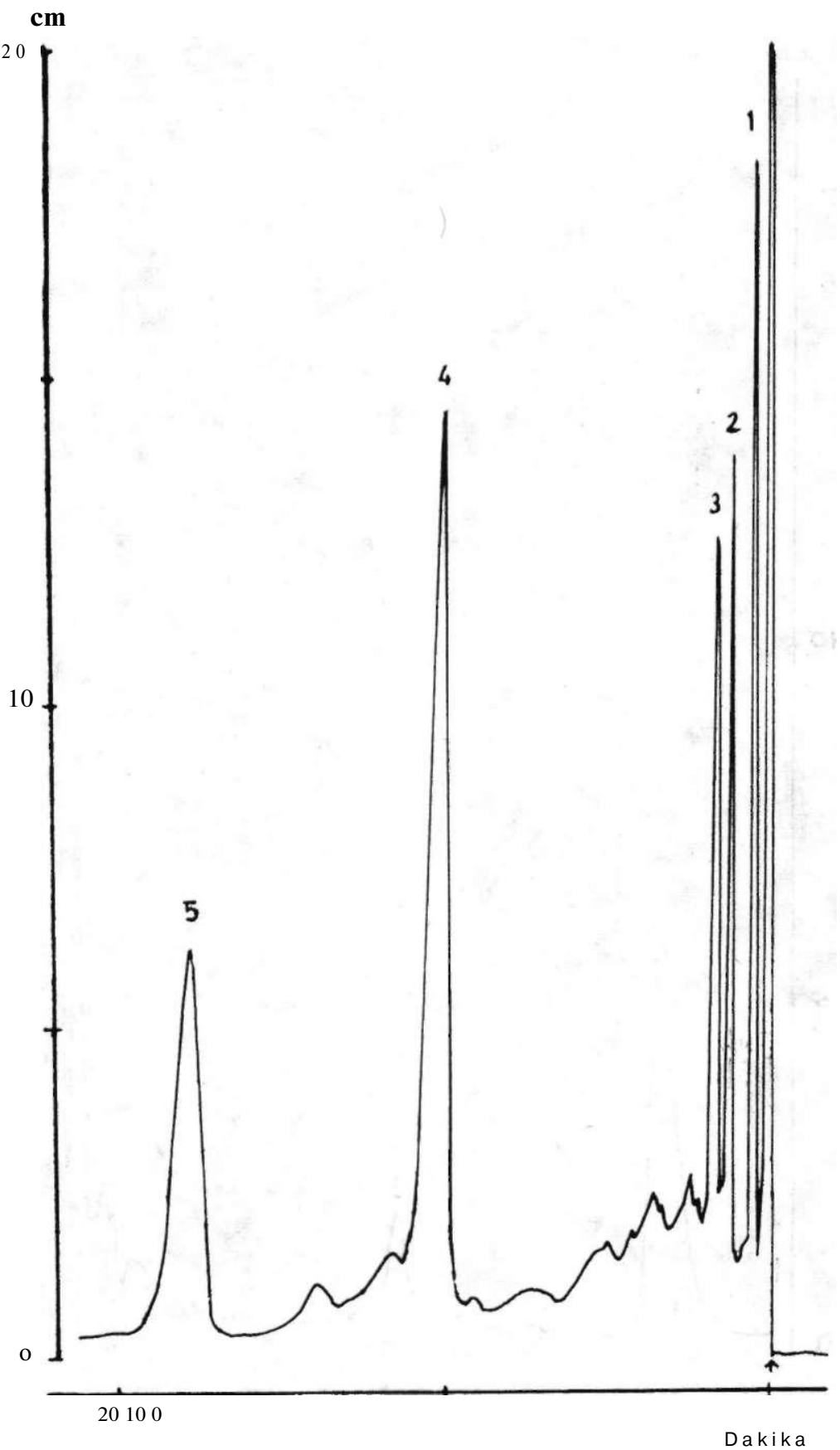

Şekil 1. Ftalat standartlarının gaz sıvı kromatografisi-ECD'deki kromatogramı 1- DEP 0) .3 \mu \mathrm{g}) 2$ - DİBP $(0.3 \mu \mathrm{g}) 3$ - DBP $(0.3 \mu \mathrm{g}) 4$ - DEHP $(0.3 \mu \mathrm{g}) 5$ - İnternal standart $(0.3 \mu \mathrm{g})$ 
Sabit faz: \% 3 SE-30

Dedektör: ECD

Azot akış hızı: $40 \mathrm{ml} / \mathrm{dak}$

Hidrojen akış hızı: $30 \mathrm{ml} / \mathrm{dak}$

Hava akış hızı: $300 \mathrm{ml} / \mathrm{dak}$

Firın sicaklığ 1 : $215^{\circ} \mathrm{C}$

Enjeksiyon sicaklığı: $260^{\circ} \mathrm{C}$

Dedektör sicaklığ $1: 280^{\circ} \mathrm{C}$

Att: 16

Kaydedici hız1: $0.5 \mathrm{~cm} / \mathrm{dak}$

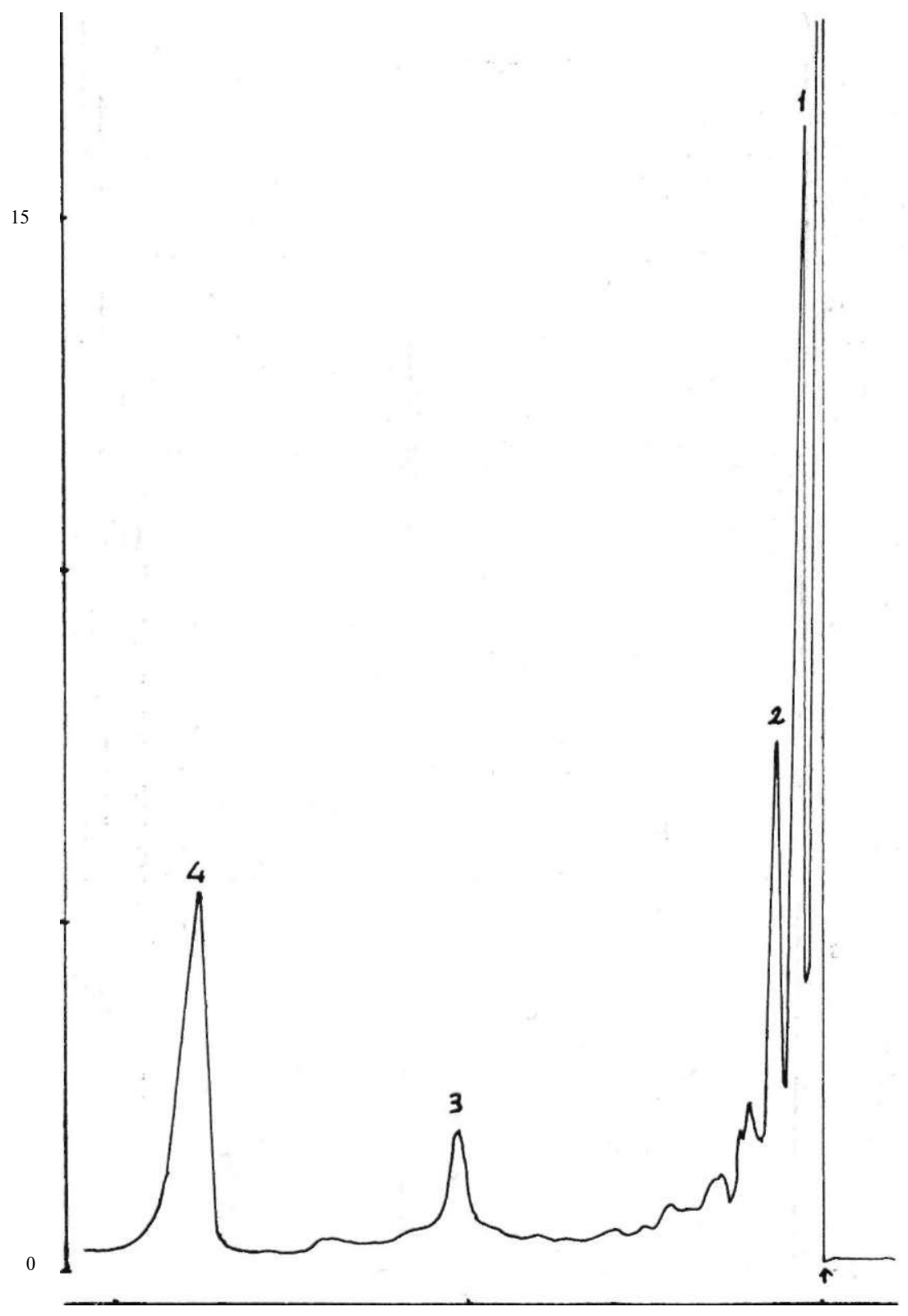

20100

Şekil 2. Bir PVC film örneğinden elde edilen ekstraktm gaz sıvı kromatografisi-ECD'deki kromatogram1 1- DEP 2- DÎBP 3- DEHP 4- İnternal standart 
netmelik"te (24) PCV'lerin gida ambalajında kullanılmasını Bakanlığın müsaadesine bağlamıştır. Gıda maddeleriyle temasta bulunabilecek diğer plastik malzemelerde ftalatların çeşitli amaçlarla kullanımı sınırlanmıştır ve en fazla toplam \% 8 oranında katılabilmektedir. İncelediğimiz PVC örneklerindeki ftalat oranları konulan bu sınırın altında bulunmuştur.

Sonuç olarak günümüzde PVC plastik malzemelerin gida ambalajı olarak kullanımının, kısıtlı da olsa devam etmesi, bu plastiklere katılan ftalatların toksik etkilerine maruz kalmayı kaçınılmaz hale getirmektedir. Her nekadar önlem olarak bazı sınırlamalar getirilmiş ise de devamlı kontroller ile bu ve bunun gibi katkı maddelerinin kat1lış oranları, gıdaya geçişleri ve getirebilecekleri sonuçlar sürekli gözlenmelidir.

\section{LİTERAT ÜR}

1- Eckardt, R.E., Hindin, R., "Health hazards of plastics" J.Occup. Med., 15, 808 (1973).

2- Eckardt, R.E., Hindin, R., "Occupational and environmental health hazards in the plastic industry": Env. Hlth. Persp., 17, 103 (1976).

3- Karstadt, M., "PCV: Health implications and production trends" Env. Hlth. Perp., 17, 107 (1976).

4- IARC, "Vinyl chloride, polyvinyl chloride and vinyl chloride-vinylacetate copolymers. In: IARC Monographs on the Evaluation of the Carcinogenic Risk of Chemicals to Humans. Vol. 19. Some monomers, Plastics and Synthetic Elastomers and Acrolein" International Agency for Research on Cancer, Lyon (1979).

5- Fishbein, L., "Toxicity of the components of poly (vinylchloride) polymers I. Additives" International Symposium on Occupational Hazards Related to Plastics and Synthetic Elastomers, November 22-27, Espoo, Finland (I9982).

6- Nielsen, J., Akesson, B., Skerfvirig, S.,"Phthalate ester exposure-air levels and health of workers processing Polyvinylchloride" Am. Ind. Hyg. Assoc. J., 46, 643 (1985).

7- Vural, N., "Türkiye'de kullanılan plastik besin kaplarının toksikoloji açısından değerlendirilmesi" Ankara Ecz. Fak. Mec, 7, 163 (1977).

8- Yiğit, V., Evranos, Ö., "Gıda ambalajlanmasında kullanılan plastikler üzerinde araştırmalar" T ÜBİTAK Marmara Bilimsel ve Endüstriyel Araştırma Enstitüsü Beslenme ve Gıda Teknolojisi Ünitesi, Yayın No 29 (1978).

9- Mori, S., "Contamination of water and organic solvents stored in plastic bottles with phthalate ester plasticizers" Anal. Chim. Acta, 108, 325 (1979).

10 - Yiğit, V., "Plastik Ambalaj maddelerinde gıdaya geçen bazı katkı maddeleri üzerinde araştırmalar" TÜBİTAK Marmara Bilimsel ve Endüstriyel Araştırma Enstitüsü Beslenme ve Gıda Teknolojisi Ünitesi, Yayın No 41 (1980).

11 - Figge, K., "Migration of components from plastic packaging materials into packed goods-test methods and diffusion models" Prog. Polym. Sci., 6, 187 (1980). 
12- IARC, "Di (2-Ethylhexyl) phhthalate. In: IARC Monographs on the Evaluation of the Carcinogenic Risk of Chemicals to Humans. Vol. 29. Some Industrials Chemicals and Dyestuffs" International Agency for Research on Cancer, Lyon (1982).

13 - Gray, T.J.B., Butterworth, K.R., Gaunt, I.F., Grasso, P., Gangolli, S.D., "Shortterm toxicity study ofdi (2-ethylhexyl) phthalate in rats" Food Cosmet. Toxicol., 15, 389 (1977).

14- Singh, A.R., Laurence, W.H., Autian, J., "Maternal-fetal transfer of 14-di-2ethylhexyl phthalate and $14_{c}$-diethyl phthalate in rats" J. Pharm. Sci., 64, 1347 (1975).

15 - Nakamura. Y., Yagi, Y., Tomita, I., Tsuchikawa, K., "Teratogenicity of di (2ethylhexyl) phthalate in mice" Toxicol. Lett., 4, 113 (1979).

16- Oishi, S., Hiraga, K., "Testicular atrophy induced by phthalic acid esters: Effect on testosterone and zinc concentrations" Toxicol. Appl. Pharmacol., 53, 35 (1980).

17 - Annual book of ASTM Standards, Part-35, D 3421-75, p. 876 (1982).

18 - Campbell, G.B., Foxton, A.A., Worsdall, R.L., "Identification of plasticizers in PVC compounds by thin layer chromatography" Lab. Pract., 19, 369 (1970).

19- Urbanski, J., Czerwinski, W., Janicka, K., Majewska, F., Zowall, H., Handbook of Analysis of Synthetic Polymers and Plastics, p. 357, Ellis Horwood Ltd. England (1977).

20 - Vessman, J., Rietz, G., "Determination of di (ethylhexyl) phthalate in human plasma and plasma proteins by electron capture gas chromatography" J. Chrom., 100, 153 (1974).

21 - Giam, C.S., Chan, H.S., Neff, G.S., "Sensitive method for determination of phthalate ester plasticizers in open-ocean biota samples" Anal. Chem., 47, 2225 (1975).

22 - Burns, T., Hayes, W.P., Steele, P., "Identification and determination of primary plasticizers in polyvinyl chloride calendered formulations" J. Chrom., 103, 241 (1975).

23 - Mori, S., "Identification and determination of phthalate esters in river water by highperformance liquid chromatography" J. Chrom., 129, 53 (1976).

24 - S.S.Y.B., Gıda Maddeleri ile Temasta Bulunan veya Bulunmak Üzere İmal Edilen Plastikler Hakkında Yönetmelik, Başbakanlık Basımevi, Ankara (1980). 